\title{
Editorial
}

\section{Lessons from the public health response to Ebola}

Journal of Public Health Policy (20I5) 36, I-3. doi:I0.I057/jphp.20I4.5 I; published online I I December 2014

Anything we say today about Ebola is likely to seem dated by the time it is posted online in weeks or appears in print in months. So we look back, to consider missed opportunities, and into the unknown future to avoid worldwide 'surprise' again.

How could the public health world have been so ill prepared for this year's Ebola virus disease outbreaks in Guinea, Sierra Leone, and Liberia? Although these outbreaks have grabbed the whole world's attention, we can only describe the response as 'scrambling to catch-up'.

The hemorrhagic fever caused by the Ebola virus was first described in I976 in what was then Zaire. There have been additional small outbreaks in sub-Saharan Africa. Uganda and other countries controlled outbreaks, but not without resources and an organized response.

It looks like not everyone was asleep. Lab researchers did what they are good at, and the molecular biology of the Ebola virus is rather well described and advanced in understanding. ${ }^{.}$Promising candidate vaccines and antiviral therapies have been developed but they have not progressed to licensure. ${ }^{2,3}$ Was testing and licensure left largely to an industry that saw no profit selling an Ebola vaccine to the world's poorest countries?

Research in the field has been less robust than in the laboratory. Months into the epidemic, there still seemed to be confusion about how the virus was spread. The question of whether some people are more likely to spread the disease than others, so-called 'super-spreaders', has lingered. More applied research is surely needed. We learned recently that management of waste disposal - from bodily fluids to personal protective equipment and mattresses - remains inadequately studied. Does everything need to be buried or burned? What works efficiently?

Perhaps it is unfair to expect the world's major research institutes - the Institut Pasteur, the Karolinska, or the US National Institutes of Health to put more researchers in the field. But, is there an explanation for the World Health Organization's (WHO) failure to organize assistance for 
countries with inadequate resources; to help them prepare for Ebola and other infectious disorders? In the case of Ebola, WHO knew that with preparation and resources, the disease had, in the past, been successfully contained. New global interest in noncommunicable diseases ${ }^{4}$ must not absolve public health officials for their failure to prepare for infectious disease outbreaks.

Médecins Sans Frontières (MSF) has sent doctors and nurses into the field to help where resources are scarce. They also conduct field research. MSF's applied research, organized by Epicentre MSF in Paris. Epicentre studies field operations of MSF to learn what works and what does not. They learn what knowledge, strategies, and resources are needed, and how to provide care and protection. MSF developed guidance for the use of personal protective equipment.

In June 20I4 MSF was outspoken, calling for a robust response and stating that the outbreak was 'out of control' and that they had reached their limit in being able to care for patients with Ebola virus disease in 60 locations across Liberia, Guinea, and Sierra Leone. Was anyone listening? It took 6 weeks until WHO deemed Ebola a 'Public Health Emergency of International Concern' and called for a coordinated international response. Countries facing occasional imported cases were in a panic about how to respond at home, while thousands of people in West Africa became infected with Ebola.

Our list of 'pending' infectious challenges is far from exhaustive, but it confirms that there are many threats out there. Influenza has received some attention. The coronaviruses - Middle East Respiratory Syndrome and Severe Acute Respiratory Syndrome - and the paramyxoviruses - Nipah virus - remain serious threats to health globally. ${ }^{5,6}$ Current efforts to control multi-drug resistant tuberculosis are dangerously 'out of step' with this grave peril. ${ }^{7,8}$ Mosquito control needs to be reinforced so that Chikungunya and Dengue can be prevented. We must look ahead at the full range of threats.

Can we learn from Ebola? We must make sure that lab research, plus applied research and field studies, and the resources for care and prevention will be developed now so that we will not be 'surprised' in the future as we seem to have been with Ebola.

\section{References}

I. Sullivan, N., Yang, Z.-Y. and Nabel, G.J. (2003) Ebola virus pathogenesis: Implications for vaccines and therapies. Journal of Virology 77(I 8): 9733-9737. 
2. Giesbert, T.W., Bausch, D.G. and Feldmann, H. (2010) Prospects for immunization against Marburg and Ebola viruses. Reviews in Medical Virology 20(6): 344-357.

3. Giesbert, T.W. et al (20I0) Postexposure protection of non-human primates against a lethal Ebola virus challenge with RNA interference: A proof-of-concept study. The Lancet 375(9729): I 896-I905.

4. World Health Organization. (20I0) Global Status Report on Noncommunicable Diseases 20I0, http://www.who.int/nmh/.../ncd_report2oro/en/.

5. Perl, T.M., McGeer, A. and Price, C.S. (20I4) Medusa's ugly head again: From SARS to MERSCoV. Annals of Internal Medicine I60(6): 432-433.

6. Luby, S. (20I3) Pandemic potential of Nipah virus. Antiviral Research IO०(6): $38-43$.

7. MSF. (20I4) Out of step: Deadly implementation gaps in the TB response. A survey of TB diagnostic and treatment practices in eight countries, October, http://www.doctorswithoutborders .org/document/out-step-deadly-implementation-gaps-tb-response, accessed 5 November 2014.

8. Berkelman, R.L., Cassell, G, Whitney, E. and Keshavjee, S. (2014) Shifting gears to control drugresistant tuberculosis. Clinical Infectious Diseases 59(6): 908-910.

Anthony Robbins

Co-Editor

Ruth Berkelman

Member, JPHP Editorial Board 